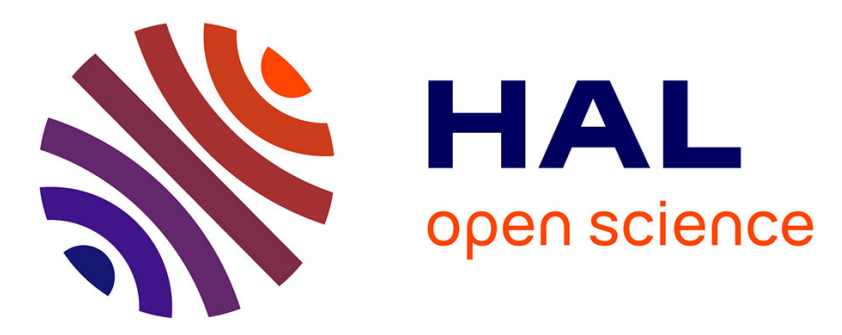

\title{
Eikonal Tomography Using Coherent Surface Waves Extracted From Ambient Noise by Iterative Matched Filtering-Application to the Large-N Maupasacq Array
}

Maximilien Lehujeur, Sébastien Chevrot

\section{- To cite this version:}

Maximilien Lehujeur, Sébastien Chevrot. Eikonal Tomography Using Coherent Surface Waves Extracted From Ambient Noise by Iterative Matched Filtering-Application to the Large-N Maupasacq Array. Journal of Geophysical Research: Solid Earth, 2020, 125 (6), 10.1029/2020JB019363 . hal02988840

\author{
HAL Id: hal-02988840 \\ https://hal.science/hal-02988840
}

Submitted on 18 Nov 2020

HAL is a multi-disciplinary open access archive for the deposit and dissemination of scientific research documents, whether they are published or not. The documents may come from teaching and research institutions in France or abroad, or from public or private research centers.
L'archive ouverte pluridisciplinaire HAL, est destinée au dépôt et à la diffusion de documents scientifiques de niveau recherche, publiés ou non, émanant des établissements d'enseignement et de recherche français ou étrangers, des laboratoires publics ou privés. 
1

3

M. Lehujeur ${ }^{1}$, S. Chevrot $^{1}$
${ }^{1}$ GET, UMR 5563, Observatoire Midi Pyrénées, Université Paul Sabatier, CNRS, IRD, Toulouse, France

Key Points:

7

8

9

10

11

12 extracted from ambient noise by iterative matched filtering - Application to the large-N Maupasacq array TET, UMR 5563, Observatoire Midi Pyrénées, Université Paul Sabatier, CNRS, IRD, Toulouse, France

- Coherent surface wave trains can be extracted from ambient noise by matched filtering

- Robust phase velocity maps are obtained by eikonal tomography from the extracted coherent wave trains

- The method is applied on noise recorded by the Maupasacq array to obtain phase velocity maps of the Arzacq-Mauleon basins for periods 2-9 s

\section{Eikonal tomography using coherent surface waves}

Corresponding author: M. Lehujeur, maximilien.lehujeur@get.omp.eu 


\section{Abstract}

Standard ambient noise tomography relies on cross-correlation of noise records between pairs of sensors to estimate empirical Green's functions. This approach is challenging if the distribution of noise sources is heterogeneous and can get computationally intensive for large-N seismic arrays. Here, we propose an iterative matched filtering method to isolate and extract coherent wave fronts that travel across a dense array of seismic sensors. The method can separate interfering wave trains coming from different directions, to provide amplitude and travel time fields for each detected wave front. We use the eikonal equation to derive phase velocity maps from the gradient of these travel time fields. Artefacts originating from scattered waves are removed by azimuthal averaging and spatial smoothing. The method is validated on a synthetic test and then applied to the data of the Maupasacq experiment. Rayleigh wave phase velocity maps are obtained for periods between 2 and 9 s. These maps correlate with surface geology at short period ( $\mathrm{T}<$ $3 \mathrm{~s}$ ) and reveal the deep architecture of the Arzacq and Mauleon basins at longer periods $(\mathrm{T}>4 \mathrm{~s})$.

\section{Keywords:}

Eikonal tomography, Ambient noise tomography, Surface waves, large-N arrays

\section{Introduction}

Massive deployments of cheap and easy-to-install geophone nodes, which were so far devoted to active source acquisitions for the oil and gas industry, have recently received increasing interest from the academic world for passive imaging studies (e.g., de Ridder \& Dellinger, 2011; de Ridder \& Biondi, 2015; Lin et al., 2013; Mordret et al., 2013; Hand, 2014). These large-N passive deployments open important new perspectives for the studies of active faults (Ben-Zion et al., 2015; Roux, Moreau, et al., 2016; Taylor et al., 2019; Y. Wang et al., 2019), reservoirs (Vergne et al., 2017), volcanoes (Hansen \& Schmandt, 2015; Brenguier et al., 2016; Nakata et al., 2016), glaciers (Roux, Gimbert, et al., 2016), or landslides (J. Wang et al., 2008).

In the period range 1-10 s, i.e. in the so-called "secondary microseismic noise" band, the predominant source of noise is the interaction between oceanic waves and the solid earth, which produces surface waves that can be recorded by seismic stations located far away in the middle of continents (Longuet-Higgins, 1950). These surface waves in the 
ambient noise have been extensively used for passive imaging of the crust (e.g., Shapiro et al., 2005; Lin et al., 2008, 2009; Ritzwoller et al., 2011). The standard approach consists in estimating empirical Green's functions from the correlation of noise recorded by pairs of sensors (Lobkis \& Weaver, 2001; Shapiro \& Campillo, 2004). This approach has proven especially well suited for dense seismic arrays, because it can be fully automatized and can thus be applied to massive data sets. Several variants of the method have been proposed to handle the case of an imperfectly homogeneous noise distribution (Curtis \& Halliday, 2010; Wapenaar et al., 2011; Roux, Moreau, et al., 2016; Ermert et al., 2017) or to jointly invert for the velocity model and the source distribution (Yao \& van der Hilst, 2009; Fichtner et al., 2017; Sager et al., 2018).

Alternatively, dense seismic arrays allow seismologists to measure directly the local velocity and propagation direction of a wave front. For example, the Progressive Multichannel Cross-Correlation method (PMCC, Cansi, 1995) estimates these parameters using phase differences computed over triangles of close stations. This method has been later adapted to large aperture arrays such as the USArray Transportable Array (Fan et al., 2018). Local phase velocities can also be estimated by gradiometry (de Ridder \& Biondi, 2015) or by local beamforming (Roux \& Ben-Zion, 2017). Unlike classical ambient noise tomography, these approaches remain applicable even if the distribution of sources is highly heterogeneous. However, since they rely on a limited subset of stations, they are more vulnerable to the effects of interfering arrivals, which can strongly bias the measurements.

In this study, we introduce a matched filtering method to isolate and extract surface wave fronts from the ambient noise using a dense seismic array. We then exploit the phase of the extracted wave fronts to derive phase velocity maps by eikonal tomography (Lin et al., 2009). We apply the method on the ambient noise field recorded by the largeN Maupasacq (Mauleon Passive Acquisition) seismic array.

The paper is organized as follows. In section 2, we describe the Maupasacq experiment and characterize the ambient noise field recorded in the 1-10 s period band. We find evidence for highly directive and energetic surface wave trains that are generated in the oceans. Section 3 details the matched filtering method that can isolate these coherent wave fronts. We determine phase velocity maps from the phase gradient of these surface wave fields with the eikonal equation. In section 4 , the method is tested and val- 
idated on a synthetic data set that mimics the Maupasacq acquisition. In section 5 , it is applied to the Maupasacq data set to obtain phase velocity maps of the area for periods between 2 and $9 \mathrm{~s}$. After a preliminary geological interpretation of our results, we discuss some perspectives opened by this new way to exploit data from dense seismic arrays.

\section{Characterization of ambient noise recorded during the Maupasacq experiment}

\subsection{The Maupasacq experiment}

The Maupasacq array (presented in Polychronopoulou et al., 2018) operated from March to October 2017 in the Mauleon basin (western Pyrenees, France). It includes a total of 442 temporary 3-component sensors (Fig. 1): 48 broad-band stations (BB) with a cut-off period of $20 \mathrm{~s}$ in complement to the 6 permanent broad band stations (PBB, cut-off period $100 \mathrm{~s}$ ) available in the area, 197 short period stations (SP, cut-off period $1 \mathrm{~s})$ and 191 geophone nodes (GN, cut-off period $0.1 \mathrm{~s}$ ). The sampling rates are $100 \mathrm{sam}-$ ples per second for the BB and SP stations, and 250 samples per second for the GN. The inner part of the network forms a regular $50 \times 30 \mathrm{~km}$ grid with an inter station spacing of about $7 \mathrm{~km}$ for the $\mathrm{BB}$, and $3 \mathrm{~km}$ for the SP. The GN were installed along 5 lines in the WNW-ESE direction with a spacing of $1 \mathrm{~km}$, and along 3 lines in the SSW-NNE direction with a spacing of $1.5 \mathrm{~km}$. The dense part of the array is surrounded by two circles of BB and SP stations extending the total aperture to about $120 \times 130 \mathrm{~km}$.

[Fig. 1]

\subsection{Characterization of the ambient noise field}

In this work, we focus on the ambient wave field in the 1-10 s period band, which roughly corresponds to the period band of secondary microseismic noise. We first characterize the noise recorded by the Maupasacq array in the spectral, spatial and temporal domains.

\subsubsection{Power spectral density and noise polarization}

A spectrogram of the vertical component record at permanent station ATE during the Maupasacq experiment is shown in Figure 2a. Several higher energy patches emerge 


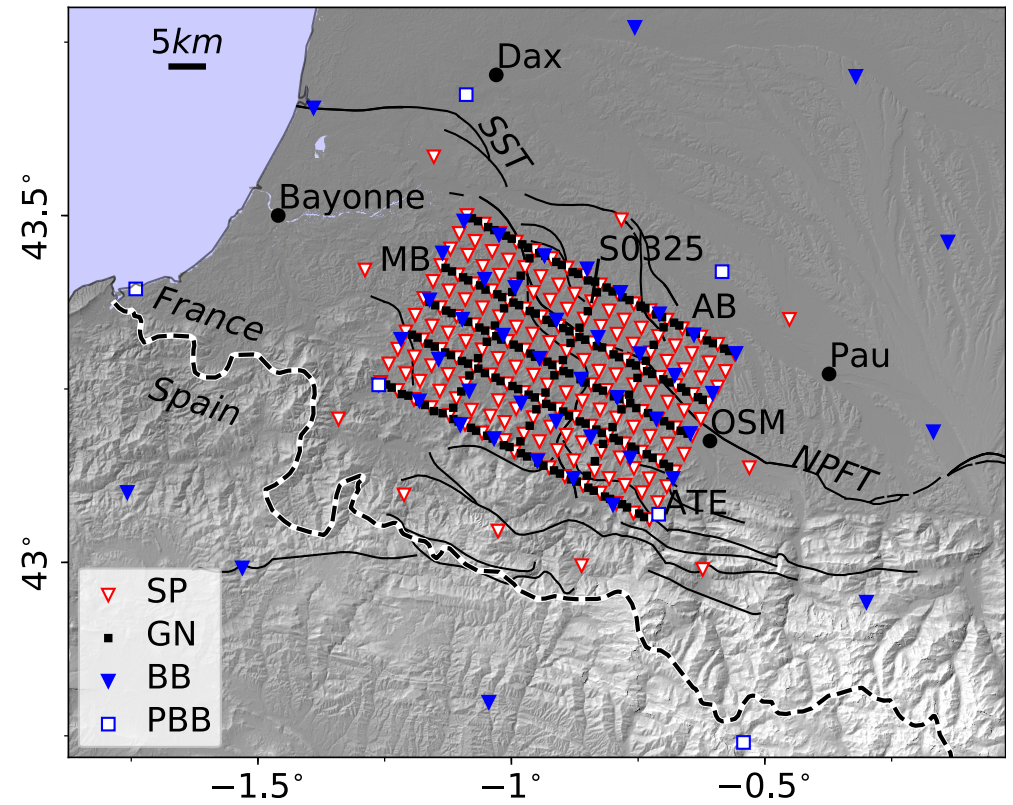

Figure 1. Map of the Maupasacq array. BB: broad-band, PBB: permanent broad-band, SP: short-period, GN: Geophone nodes. OSM: Oloron-Sainte-Marie, AB: Arzacq Basin, MB: Mauleon Basin, NPFT: North Pyrenean Front Thrust, SST: Sainte-suzanne Thrust. The solid lines indicate some of the main faults of the area after Saspiturry et al. (2019). The dashed line corresponds to the French-Spanish border. 

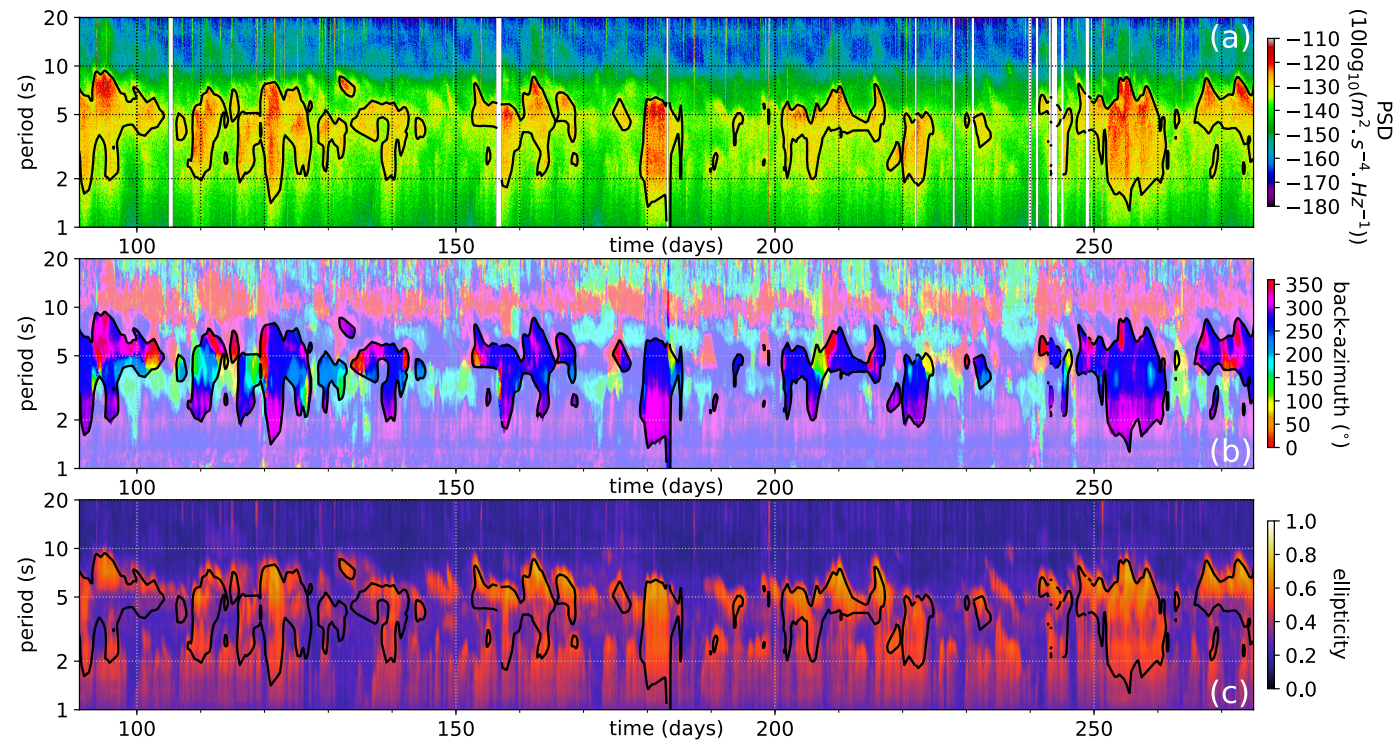

Figure 2. (a) Power spectral density of the vertical component of the permanent broad-band station ATE, with a time resolution of 1 hour, from April 1st to October 2nd, 2017. Amplitudes are expressed in $\mathrm{dB}$ relative to $1 \mathrm{~m}^{2} \cdot \mathrm{s}^{-4} \cdot \mathrm{Hz}^{-1}$. Black contours correspond to the $-132 \mathrm{~dB}$ noise level. (b) Polarization back-azimuth averaged over all the broad-band stations during the same period. The measurements associated to low noise levels are shadowed using the same contours as (a). (c) Average ellipticity. A value of 1 corresponds to circular polarization, while a value of 0 corresponds to linear polarization.

in the period band of the secondary microseismic peak (Fig. 2a, contoured patterns). The upper period bound of these patches extends to about $10 \mathrm{~s}$ at the beginning and end of the recording period (e.g., days 95 or 255) and decreases to 6-7 s during summer (e.g., day 180). This change in noise amplitude and frequency content reflects the seasonal decline in the intensity and number of oceanic storms during summer in the northern hemisphere (Stutzmann et al., 2000).

[Fig. 2]

To further characterize the azimuthal distribution of the noise sources over time and period and to determine the wave type that dominates during the high energy patterns observed in the power spectral analysis, we estimate the dominant polarization state of the ambient noise for periods between 1 and $20 \mathrm{~s}$ using the BB and PBB stations (Figure 1). The three-component waveforms are cut into consecutive 1 hour windows. The seismic records are deconvolved from the instrumental response, detrended, tapered, and 
down-sampled at 2.5 samples per seconds. Inside each one-hour window, we compute the ensemble average inter components cross-spectral matrix using a 400 s sliding window with $50 \%$ overlap. The dominant polarization is then determined from the eigenvalue decomposition of the ensemble average cross-spectral matrix at each period (Park et al., 1987). The complex eigenvector associated with the highest eigenvalue corresponds to the dominant polarization component of the signal. The real and imaginary parts of this vector correspond to the semi-major and semi-minor axes of the polarization ellipse, respectively. For each station, we estimate the polarization ellipticity as the ratio between the norms of the imaginary and real parts of the first eigenvector (Vidale, 1986). The propagation direction is estimated from the azimuth of the real part of the first eigenvector. The $180^{\circ}$ ambiguity of the propagation direction is resolved by assuming a retrograde polarization. The polarization attributes are then averaged for all the broad band stations of the array in the time-period domain (Figure 2b, c). The average propagation direction is obtained by averaging the ellipticity orientation observed at each station:

$$
\beta=\arg \left(\frac{1}{N} \sum_{j=0}^{N-1} e^{i \beta_{j}}\right),
$$

where $\beta_{j}$ is the back azimuth estimated at station $j$, in radians, and arg denotes the complex argument.

The high energetic patterns observed in the vertical component spectrogram (Fig. 2a) are characterized by higher average ellipticity (Fig. 2c), which confirms the predominance of Rayleigh waves. As can be seen in Fig. 2b, these waves originate mostly from a few specific directions in good agreement with the dominant noise directions previously reported by Chevrot et al. (2007) in the nearby Quercy region : N275 (Galicia), N340 (Northern Atlantic) and N130 (Mediterranean sea, see for example day 206).

\subsubsection{Beamforming analysis}

To complement the polarization study, we analyse the vertical component records using beamforming at several periods between 2 and $9 \mathrm{~s}$. We introduce the plane wave beamforming operator (e.g., Jensen et al., 2000):

$$
B(\mathbf{s}, \omega)=\frac{1}{N} \sum_{j=0}^{N-1} U\left(\mathbf{r}_{j}, \omega\right) e^{i \omega \mathbf{s} \cdot\left(\mathbf{r}_{j}-\tilde{\mathbf{r}}\right)},
$$


where $\mathbf{s}$ is the horizontal slowness vector, $\omega$ the angular frequency, $\mathrm{N}$ the number of stations, $U\left(\mathbf{r}_{j}, \omega\right)$ the Fourier transform of the wave field observed at station $j$ located in $\mathbf{r}_{j}$, and $\tilde{\mathbf{r}}$ the reference location, taken here as the center of the array. To account for the dispersive nature of surface waves, we evaluate the beam-power near a center pulsation $\tilde{\omega}$ using spectral integration of the band-pass filtered traces:

$$
E(\mathbf{s}, \tilde{\omega})=\frac{1}{2 \pi} \int|G(\omega, \tilde{\omega}) \cdot B(\mathbf{s}, \omega)|^{2} \mathrm{~d} \omega,
$$

where $\mathrm{G}$ denotes the Fourier domain Gaussian band-pass filter centered on pulsation $\tilde{\omega}$ with a bandwidth controlled by a coefficient $\alpha$ (e.g., Bensen et al., 2007):

$$
G(\omega, \tilde{\omega})=e^{-\alpha(|\omega / \tilde{\omega}|-1)^{2}} .
$$

Figure 3 shows the results of beamforming for two different storms recorded between days 250 and 260 (a-d) and between days 205 and 208 (e-h) at different periods. The fundamental mode Rayleigh waves correspond to phase velocities near $2.6 \mathrm{~km} / \mathrm{s}$ at $2 \mathrm{~s}$ period and $3.1 \mathrm{~km} / \mathrm{s}$ at $9 \mathrm{~s}$ period. The propagation directions obtained by beamforming are in excellent agreement with the polarization analysis (Fig. 2a). In particular, prominent energetic arrivals are detected from back azimuths $\mathrm{N} 275^{\circ}, \mathrm{N} 340^{\circ}$ and $\mathrm{N} 130^{\circ}$. The relative amplitudes of these noise sources vary strongly as a function of the time interval considered and the period. For example, the signal recorded between days 250 and 260 (Fig. 2a) is dominated by noise sources from Galicia for periods between 2 and $6 \mathrm{~s}$ (Fig. 3b-d and blueish colors on Fig. 2b), while the northern direction dominates at periods near $9 \mathrm{~s}$ (Fig. 3a and pinkish colors on Fig. 2b). Secondary arrivals are also observed from the Mediterranean sea at periods below $3 \mathrm{~s}$ (Fig. 3c,d). These Mediterranean sources are rarely dominant. Most of the time they are masked by the energetic arrivals coming from the northern and western directions, which explains why they are under represented in the polarization diagram in Fig. 2b.

Beamforming analysis also revealed a weak but pervasive noise source with a dominant period around $7 \mathrm{~s}$ that produces waves with a very fast apparent phase velocity, indicating a nearly vertical incidence (e.g., Figure. 3e). Similar waves have been reported in the literature and attributed to distant oceanic sources (e.g., Landès et al., 2010; Meschede et al., 2017; Pedersen \& Colombi, 2018). They could be responsible for the spurious large 

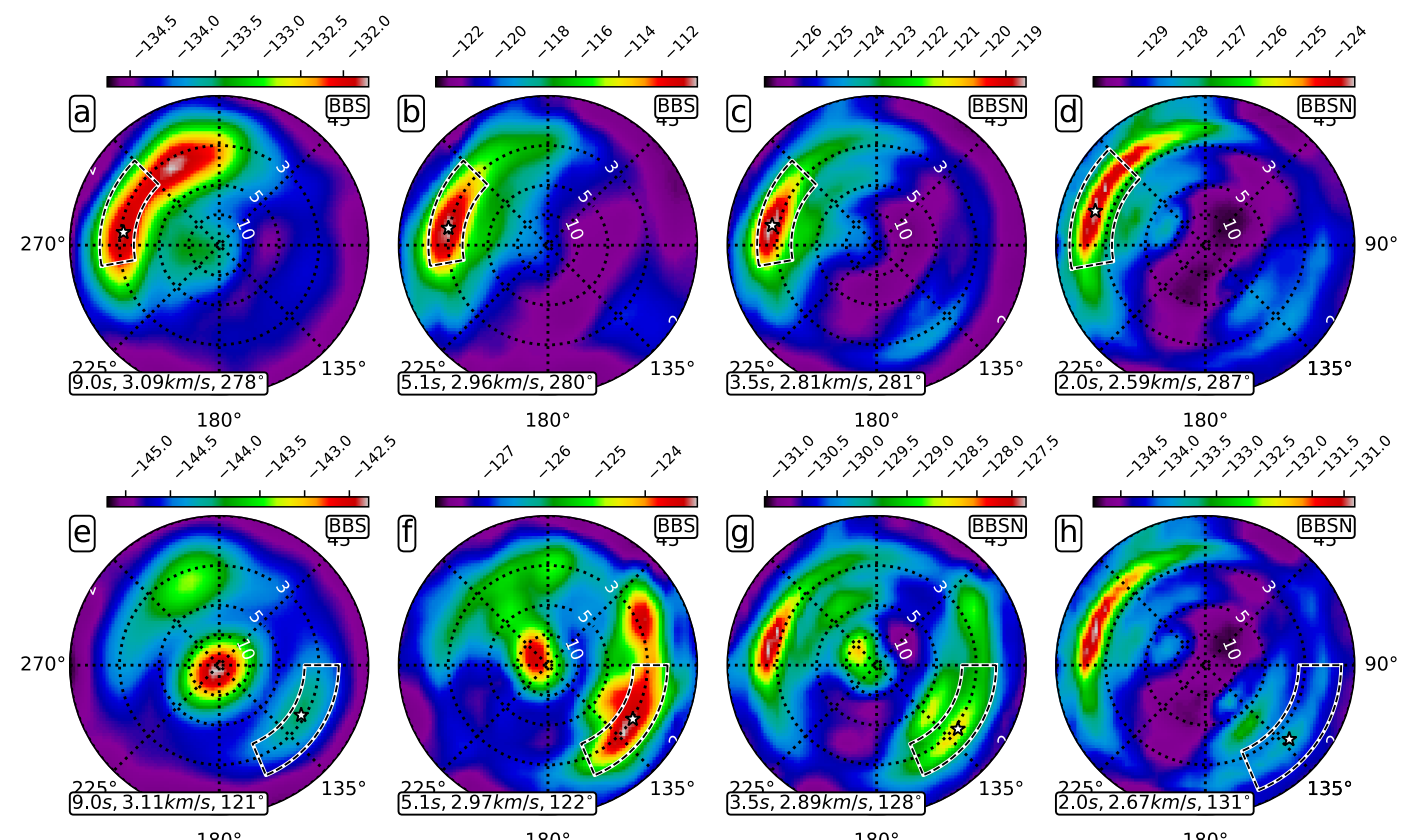

$180^{\circ}$
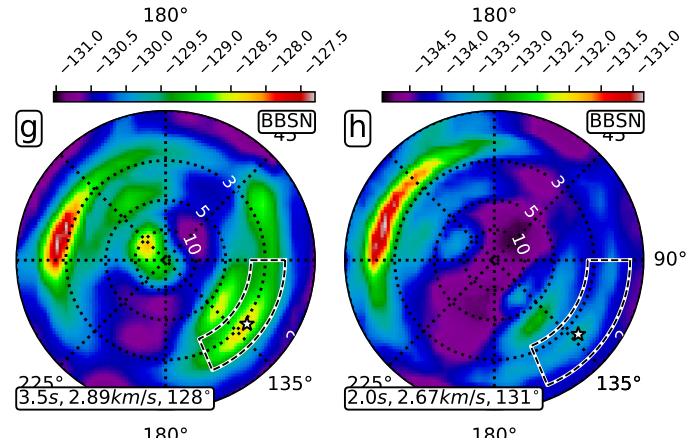

Figure 3. Beam power estimates for two storms recorded from days 250 to 260 (a-d) and days 205 to 208 (e-h) for several periods between 2 and 9 s. The amplitudes are expressed in $\mathrm{dB}$ relative to $1 \mathrm{~m}^{2} \cdot \mathrm{s}^{-2} \cdot \mathrm{Hz}^{-1}$. The angles correspond to back-azimuths in degrees and the radial ticks correspond to phase velocities in $\mathrm{km} / \mathrm{s}$. All the station are used for the periods between 2 and $3.5 \mathrm{~s}$ (label BBSN) and only the BB and SP stations are used for the periods above $3.5 \mathrm{~s}$ (label BBS). The white stars indicate the local maxima found in the white dashed areas interpreted as the fundamental mode Rayleigh wave from the Galicia direction (a-d) and from the Mediterranean direction (e-h). The period, phase velocity and back-azimuth of these maxima are indicated in the legend of each diagram.

amplitude arrival near the zero lagtime that is often observed in noise correlation functions (Villaseñor et al., 2007; Taylor et al., 2019).

[Fig. 3]

\subsubsection{Coherent surface wave trains from the oceans}

In the time domain, the high energy patterns detected in the spectrogram (Fig. 2a) correspond to coherent wave trains that cross the entire array. Fig. 4a,c display the waveforms recorded during day 181 at periods $5.2 \mathrm{~s}$ and $3 \mathrm{~s}$ (see the shaded traces), where the noise comes mostly from the Galicia direction (Fig. 2b). To highlight the phase align- 
ments of the waves emitted by the dominant noise source, the seismic traces are sorted as a function of increasing distance measured along the propagation direction determined from beamforming. The black solid lines in Fig. 4a,c correspond to the reference wavelets obtained at the center of the array, using the iterative matched filtering algorithm detailed below.

\subsubsection{Concluding remarks on the nature of the ambient wave field}

We conclude from these detailed observations that the ambient wave field in the 1-10 s period band is a superposition of coherent quasi plane waves coming from a few well-defined dominant directions and not a purely diffusive wave field. The relative amplitudes of the dominant noise sources strongly vary with the time interval and with the period considered.

[Fig. 4]

\section{Methods}

\subsection{Extraction of coherent wave trains with an iterative matched filter- ing approach}

We now propose a method to separate and extract the coherent Rayleigh wave fields that we have identified in the ambient noise. The method is applied to consecutive and non overlapping one-hour long time windows, detrended, deconvolved from the instrument response and filtered with a Gaussian band-pass filter near a central pulsation $\tilde{\omega}$. No temporal or spectral normalization (e.g., Bensen et al., 2007) is applied to the data. The algorithm involves three successive steps, which are described in more details in the following:

- A beamforming, which allows us to estimate the apparent slowness and back azimuth of the dominant noise source. These beam parameters are used to obtain an initial reference wavelet at the center of the array.

- An iterative matched filter. This step iteratively improves the reference wavelet and the values of time and amplitude fields at each station.

- A subtraction of the matched wave field from each trace. 

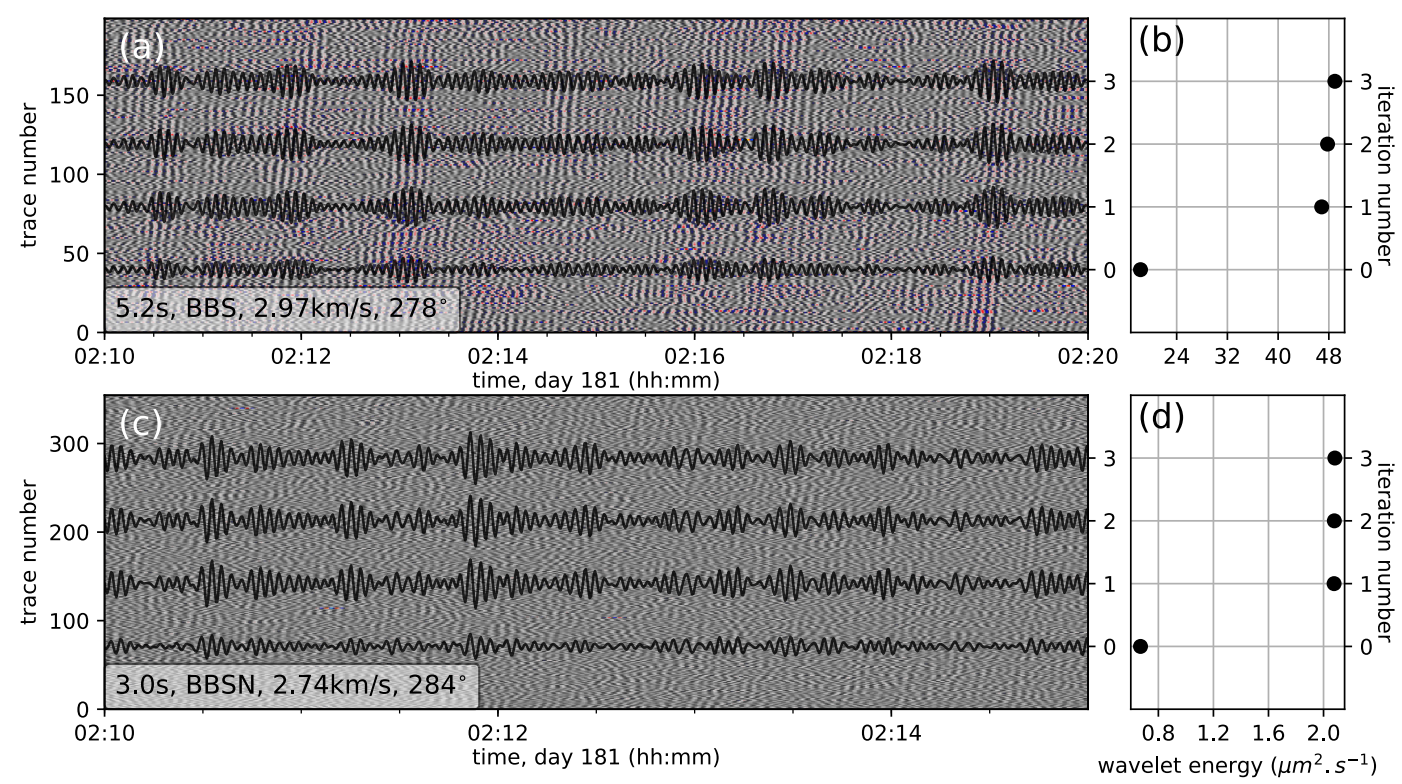

Figure 4. Oceanic wave trains and convergence of the reference wavelet. (a) The background gray-scaled field corresponds to the vertical component waveforms recorded by the $\mathrm{PBB}, \mathrm{BB}$ and SP stations on Julian day 181. The traces are filtered around $5.2 \mathrm{~s}$ period using a Gaussian filter and sorted by increasing distance along the azimuth of the source estimated from plane-wave beamforming (step 1). The black traces show the reference wavelets obtained at each iteration of the matched filtering approach (step 2). (b) Energy of the reference wavelet shown in (a) as a function of the iteration number. (c, d), same as (a, b) near 3 s period using the PBB, BB, SP and GN stations. 
This algorithm is iterated until all the coherent wave trains are extracted and the remaining wave field is incoherent.

\subsubsection{Step 1: Beamforming and initial wavelet estimate}

In the first step, we determine the slowness vector $\mathbf{s}_{\max }(\tilde{\omega})$, which maximizes the plane-wave beam-power in the neighborhood of the center angular frequency $\tilde{\omega}$ (eq. 3). We obtain an initial estimate of the reference wavelet by forming the beam corresponding to the dominant plane wave

$$
w_{0}(\tilde{\mathbf{r}}, t)=\frac{1}{N} \sum_{j=0}^{N-1} u\left(\mathbf{r}_{j}, t+\mathbf{s}_{\max }(\tilde{\omega}) \cdot\left(\mathbf{r}_{j}-\tilde{\mathbf{r}}\right)\right)
$$

where subscript 0 indicates the first iteration, $u\left(\mathbf{r}_{j}, t\right)$ is the wave field observed at station $j$ located in $\mathbf{r}_{j}$, filtered with a Gaussian filter centered at pulsation $\tilde{\omega}$ (eq. 4), and $\tilde{\mathbf{r}}$ is the reference location, chosen at the center of the array.

\subsubsection{Step 2: Iterative matched filtering}

Matched filtering is a method used to search for a known signal in a data stream. It is a concept commonly employed in engineering to decide if and where a reference signal occurs in a background noise (e.g., radar or sonar return signals, Turin, 1960). In seismology, the method has been introduced to measure relative time delays and amplitude ratios between observed and modeled seismograms (Sigloch \& Nolet, 2006). Here, we use this approach to search for the delayed reference wavelet in each trace. To do this, we cross correlate the reference wavelet with each recorded trace. The correlation function normalized by the energy of the reference wavelet, hereafter referred to as the Matched Filter Correlation Function (MFCF) is defined as:

$$
c_{n}\left(\mathbf{r}_{j}, t\right)=\frac{w_{n}(\tilde{\mathbf{r}}, t) * u\left(\mathbf{r}_{j}, t\right)}{\int w_{n}(\tilde{\mathbf{r}}, t)^{2} \mathrm{~d} t},
$$

where $*$ denotes the time domain cross correlation operator and $n$ the iteration number. The denominator in (6) is a normalization constant which ensures that the amplitude of the MFCF at the maximum lag time is the relative amplitude of the extracted wave at station $j$ relative to the reference location. 
The MFCFs verify the wave equation because the correlation of a wave field that verifies the wave equation with any other spatially invariant signal still satisfies the wave equation (Lin et al., 2013, their equation 3). By the linearity of the correlation function, this assertion holds true if $u$ is the superposition of several wave fields verifying the wave equation.

The maximum of the MFCF occurs at lag-time $T_{n}\left(\mathbf{r}_{j}, \tilde{\omega}\right)$, which corresponds to the time delay between the station $j$ and the reference location in the direction of propagation of the dominant coherent wave. We then relax the plane-wave assumption. The traces are realigned with the new time delays and stacked to determine a new reference wavelet

$$
w_{n+1}(\tilde{\mathbf{r}}, t)=\frac{1}{N} \sum_{j=0}^{N-1} u\left(\mathbf{r}_{j}, t+T_{n}\left(\mathbf{r}_{j}, \tilde{\omega}\right)\right)
$$

that will be used at iteration $n+1$ to recompute the MFCF according to eq. (6). The process is iterated until convergence, i.e. until the energy of the reference wavelet reaches a plateau, which usually occurs after a few iterations.

Examples of wavelets obtained at the successive iterations of the matched filtering algorithm are shown in Fig. 4a,c (black solid lines). The right part of Fig. 4 (b,d) shows the variation of the wavelet energy as a function of the iteration number. The final wavelet energy is usually 2 to 4 times larger than the energy of the initial plane-wave estimate. This increased energy results from an improved alignment of the seismic traces, which accounts for the lateral variations of phase velocity beneath the Maupasacq array. From the last version of the MFCF, noted $c_{f}$, we get the travel time and amplitude at each station, measured as the maximum lag time and maximum amplitude of $c_{f}$

$$
\left\{\begin{array}{c}
T\left(\mathbf{r}_{j}, \tilde{\omega}\right)=\operatorname{argmax}\left\{t \rightarrow c_{f}\left(\mathbf{r}_{j}, t\right)\right\} \\
A\left(\mathbf{r}_{j}, \tilde{\omega}\right)=c_{f}\left(\mathbf{r}_{j}, T\left(\mathbf{r}_{j}, \tilde{\omega}\right)\right)
\end{array}\right.
$$

Figure 5 illustrates the travel time and amplitude of the dominant wave field at $5.2 \mathrm{~s}$ period extracted from a one-hour long noise time window.

[Fig. 5] 

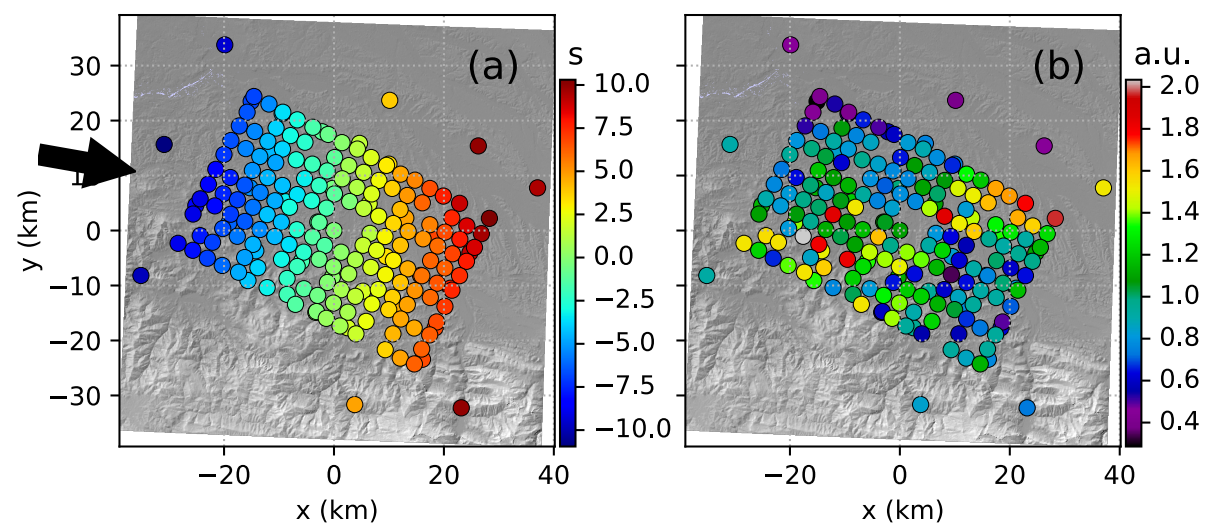

Figure 5. Travel time (a) and amplitude fields (b) of the MFCFs at $5.2 \mathrm{~s}$ period obtained for one hour of signal recorded on Julian day 181, between 2 and 3 a.m. (UTC) by the BB, PBB and SP stations. The amplitude and travel time fields correspond to a dominant noise source from back-azimuth $277^{\circ}$ (black arrow) detected at the first iteration of the 3-step procedure.

\subsubsection{Step 3 : Subtraction of the dominant wave field from the signal}

The last step of the algorithm consists in subtracting the wave field matched to the reference wavelet from the traces. The matched wave field is built from a time shifted and scaled version of the reference wavelet at each station:

$$
u\left(\mathbf{r}_{j}, t\right)=A\left(\mathbf{r}_{j}, \tilde{\omega}\right) \times w\left(\mathbf{r}_{j}, t-T\left(\mathbf{r}_{j}, \tilde{\omega}\right)\right) .
$$

The 3-step algorithm is then re-applied to the residual wave field, to search for secondary coherent wave fronts.

\subsubsection{Average MFCF}

For each one-hour long time window and each iteration of the 3-step matched filtering procedure, we obtain a collection of MFCFs associated to a dominant average wavenumber vector. The MFCFs obtained for similar wave vectors are averaged in order to increase the signal to noise ratio and minimize the cross-terms due to fortuitous correlations between uncorrelated noise sources (Snieder, 2004). 


\subsection{Regularized eikonal tomography}

In practice, the travel time field is only known at the locations of the seismic stations. Computing the spatial gradient of the travel time field thus requires spatial interpolation, for example using splines in tension (Lin et al., 2009; Mordret et al., 2013). But this approach gives only poor control on the value and smoothness of the velocity model. Here we formulate a regularized interpolation to search for the travel time field $\theta$ discretized on a regular Cartesian grid that minimizes the misfit with the observed travel times at each station, and such that its gradient leads to a phase slowness model that is close to an a priori slowness model. The cost function of the problem is:

$$
\begin{aligned}
f(\theta) & =\sum_{j=0}^{N-1}\left(T\left(\mathbf{r}_{j}\right)-(L \cdot \theta)_{j}\right)^{2}+\alpha^{2} \sum_{m=0}^{M-1}\left(\|\nabla \theta\|_{m}-s_{\text {prior } m}\right)^{2} \\
& +\beta^{2} \sum_{m=0}^{M-1}\left(\Delta \theta_{m}\right)^{2}+\gamma^{2} \sum_{m=0}^{M-1}\left(\Delta\|\nabla \theta\|_{m}\right)^{2} .
\end{aligned}
$$

In this expression, $T\left(\mathbf{r}_{j}\right)$ is the travel time field observed at each station, $\mathbf{r}_{j}$ the location of the $j^{\text {th }}$ station, $(L . \theta)_{j}$ the travel time estimated at station $j$ using the bi-linear interpolation operator $L, s_{\text {prior }}$ the vector containing the prior phase slowness model over the same grid as $\theta$. The dependency of $\theta, T$ and $s_{\text {prior }}$ to the center pulsation $\tilde{\omega}$ is dropped for the sake of simplicity. The first term in eq. (10) quantifies the misfit between the predicted and observed travel times. The second term measures the misfit between the eikonal phase slowness derived from the inverted parameter using the eikonal equation $\|\nabla \theta\|$ and the prior slowness model $s_{\text {prior }}$. The last two terms are penalty constraints that are introduced in order to minimize the total curvature of the travel time and slowness models respectively, which are quantified with the norm of the Laplacian (Smith \& Wessel, 1990). The parameters $\alpha, \beta$ and $\gamma$ control the penalty constraints that regularize the solution. The inverse problem (10) is solved with a conjugate gradient algorithm. The travel time model $\theta$ used to initiate the inversion is computed in the prior slowness model $s_{\text {prior }}$ using the fast marching method (FMM, Sethian, 1996). The inversion is first applied to the longest period using a homogeneous prior model. The period is then progressively decreased, using the solution of the inversion at the current period as an a priori for the next period. The regularization terms in eq. (10) allow us to smooth the inverted travel time (third term in eq. (10)) and the corresponding eikonal tomographic model (fourth term in eq. (10)), which mitigates the influence of the outliers and improves the accu- 
racy of the velocity model by canceling the interference between the incident and scattered wave fields. We adjust these regularization parameters by a systematic grid search. The criterion is to obtain smooth travel time and slowness models that provide a good fit of travel time data.

\section{Validation of the matched filtering and eikonal tomography meth- ods on a synthetic test}

\subsection{Synthetic experiment set-up}

We now validate our method with a numerical experiment. The objective of this synthetic test is to demonstrate the ability of the matched filtering method to measure travel time and amplitude fields on waves that simultaneously arrive from different directions and interfere in the time domain

We consider one-day long synthetic noise time series containing $5 \mathrm{~s}$ Rayleigh waves propagating in the structural phase velocity model shown in Fig. 6a. The synthetic noise records are built using temporal wavelets obtained by bandpass filtering white noise series around 5 s period. These noise series are then shifted in time and scaled in amplitude to simulate the propagation of the waves across the array. The phase travel time shifts and amplitude corrections at each station are obtained by resolving the scalar wave equation with a finite difference method for each noise source. As a boundary condition, we impose the displacement produced by an incident plane wave coming from the azimuth of the noise source with a phase velocity of $3.0 \mathrm{~km} / \mathrm{s}$. We implement Stacey boundary conditions to absorb the outgoing scattered wave field (Stacey, 1988). Fig. 6b,c show the phase travel time and amplitude fields modeled for an incoming wave with a backazimuth of $280^{\circ}$. We apply independent phase and envelope travel time shifts in the frequency domain. The signal is reformed afterwards in the time domain. For the envelope shifts, we use the group travel times estimated with the FMM algorithm in the synthetic group velocity model shown in Fig. 7.

We add the two synthetic noise records modelled for back-azimuths $280^{\circ}$ and $130^{\circ}$ to simulate the interference of the Atlantic Ocean and Mediterranean Sea noise sources. The amplitude of the Mediterranean source is taken as one third of the Atlantic source. Additional incoherent noise in the form of random Gaussian noise with an amplitude of 

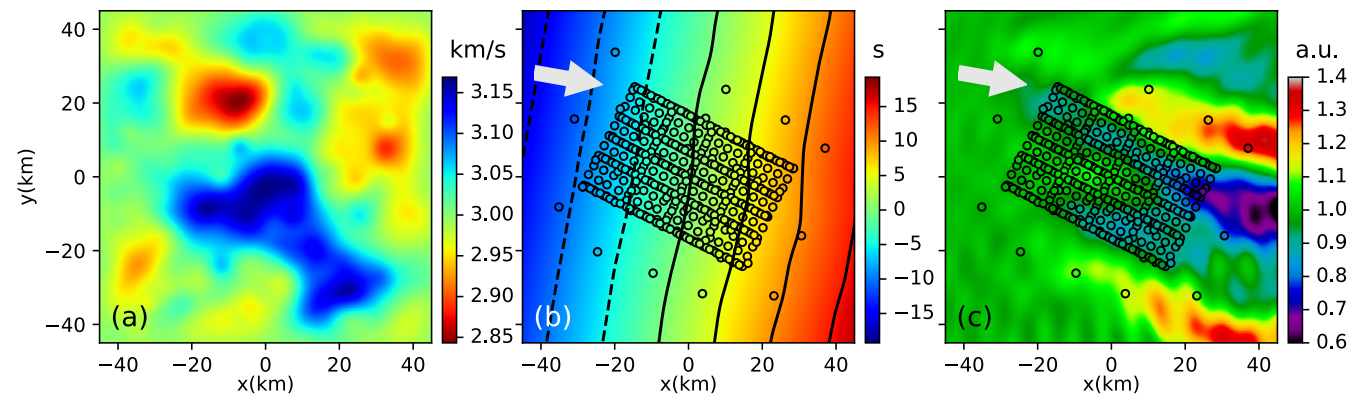

Figure 6. Synthetic surface wave modeling at period 5 s. (a) Synthetic structural velocity model for the fundamental mode Rayleigh wave at period $5 \mathrm{~s}$, expressed in $\mathrm{km} / \mathrm{s}$. (b) Travel time of the modeled wave field relative to the center of the array $(T)$, obtained by unwrapping the phase field from the solution of the wave equation. Travel time isovalues are indicated with black lines. (c) Amplitude of the modeled wave field, $(A)$ in arbitrary units. The white arrows indicate the back azimuth of the incident wave $\left(\mathrm{N} 280^{\circ}\right)$. The dots indicate the station locations.

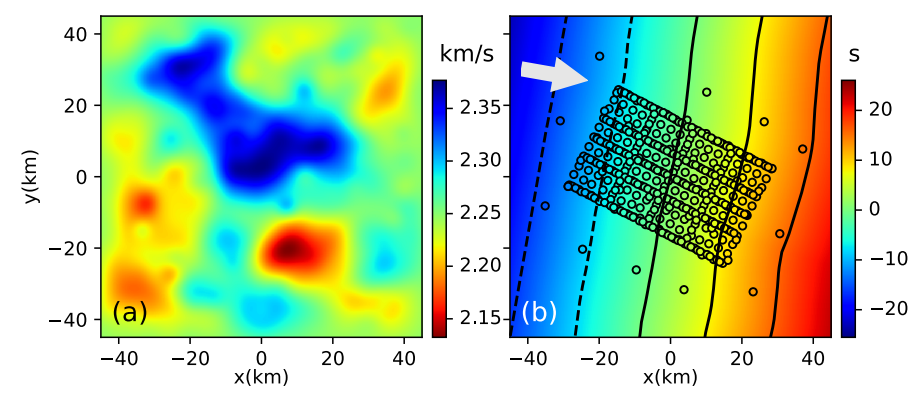

Figure 7. Synthetic surface wave modeling at period 5 s. (a) Group velocity synthetic model for the fundamental mode Rayleigh wave at period $5 \mathrm{~s}$, expressed in $\mathrm{km} / \mathrm{s}$. (b) Travel times of the Rayleigh wave envelope relative to the center coordinate in seconds, computed with the FMM algorithm for an incident plane wave from back azimuth $280^{\circ}$.

$20 \%$ of the Atlantic noise source is added to each trace to simulate instrumental noise or local uncorrelated noise sources.

[Fig. 6]

[Fig. 7]

\subsection{Results}

The 3-step matched filtering method is applied to the 1-day synthetic noise series, cut into consecutive and non-overlapping 1-hour time windows. In each window, we re- 
cover the azimuth of both the primary and secondary wave fronts after the first two iterations of the 3 -step procedure (i.e. back-azimuths $\mathrm{N} 280^{\circ}$ and $\mathrm{N} 130^{\circ}$, not shown). The phase travel times of the average MFCFs obtained at each station for the Atlantic and Mediterranean directions are shown in Figs. 8a,b. They are in good agreement with the expected travel time fields $(8 \mathrm{c}, \mathrm{d})$ obtained from the phase of the modeled wave fields for these two directions as in Fig. 6b. The lateral distribution of the amplitudes at each station from the average MFCFs also reproduces the expected ones for the two directions imposed (Fig. 9).

We invert the travel time fields at each station to obtain the eikonal phase velocity models for the two directions using eq. (10) (Fig. 10a,b). We compare them with the expected eikonal models, determined from the gradient of the expected travel time fields of Figs. 8c,d. The expected velocity models are smoothed laterally to ensure a fair comparison with the inverted phase velocity maps (Fig. 10b,d). The differences between the expected phase velocity models for back azimuths $280^{\circ}$ and $130^{\circ}$ are attributed to the errors introduced by the eikonal approximation, which discards the information carried by the amplitude field. This test validates the ability of our method to separate interfering wave fronts emitted by uncorrelated noise sources. Note that the method is also able to separate coherent wave fronts from incoherent background noise.

[Fig. 8]

[Fig. 9]

[Fig. 10]

Figure 11a shows the velocity model obtained by averaging the Atlantic and Mediterranean sources eikonal models. It is in very good agreement with the true structural model shown in Fig. 11c, at least beneath the dense part of the seismic array. The strong similarity between the eikonal model derived from a complete azimuthal coverage (Fig. 11b) and the true structural model (Fig. 11c) demonstrates that in practice eikonal tomography is sufficient to obtain accurate and robust phase velocity models provided a good azimuthal coverage.

[Fig. 11] 

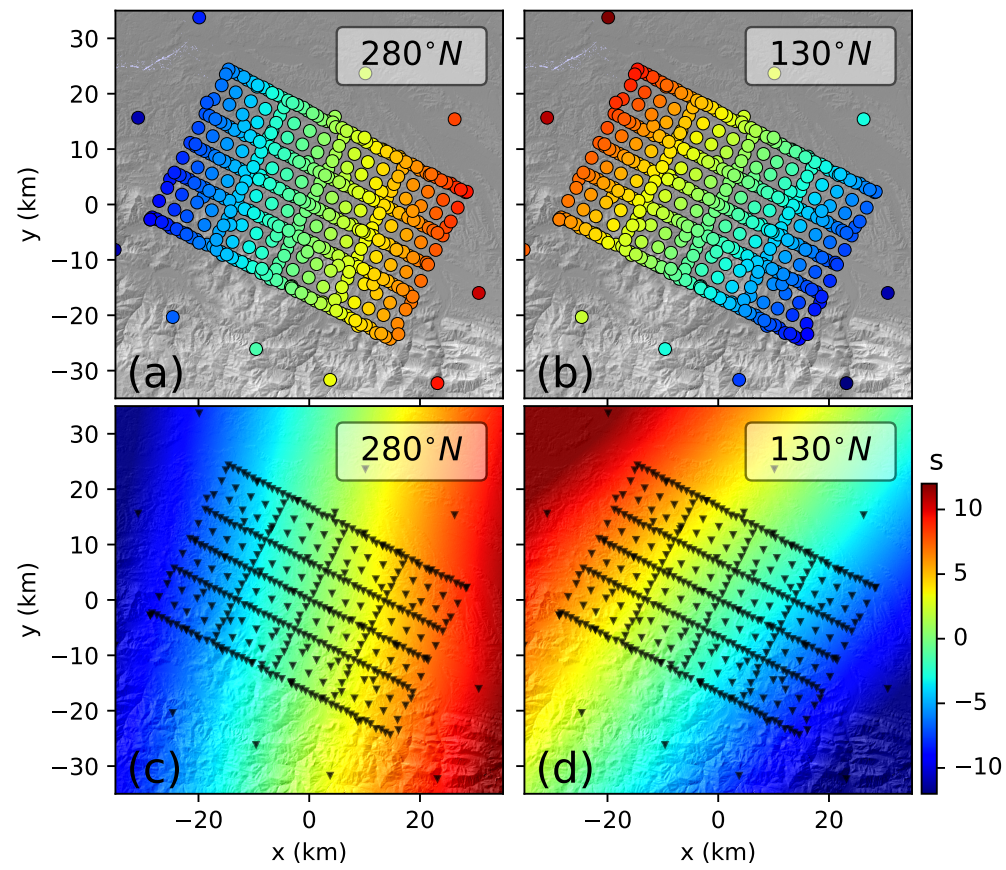

Figure 8. Results of the synthetic interfering wave fronts test for travel times. (a, b) phase travel time of the MFCFs at each station for the extracted dominant Atlantic beam (N280 ${ }^{\circ}$ a) and secondary Mediterranean beam $\left(\mathrm{N} 130^{\circ}, \mathrm{b}\right),(\mathrm{c}, \mathrm{d})$ expected travel time fields from the solution of the wave equation for an input plane wave coming from the Atlantic (c) and Mediterranean sea $(d)$. 

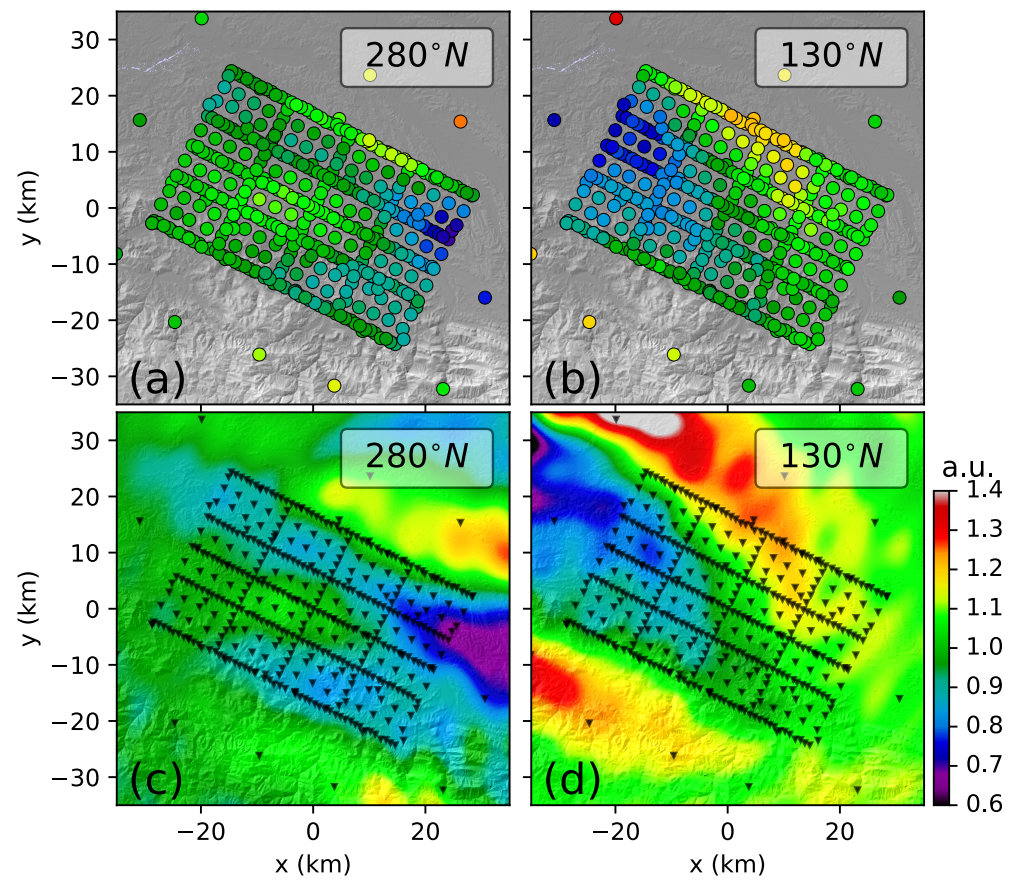

Figure 9. Results of the synthetic interfering wave fronts test for amplitudes. (a, b) amplitude of the MFCFs at each station for the dominant Atlantic beam (N280 ${ }^{\circ}$, a) and secondary Mediterranean beam $\left(\mathrm{N} 130^{\circ}, \mathrm{b}\right),(\mathrm{c}, \mathrm{d})$ expected amplitude fields from the solution of the wave equation for an input wave plane coming from the Atlantic (c) and Mediterranean sea (d). 

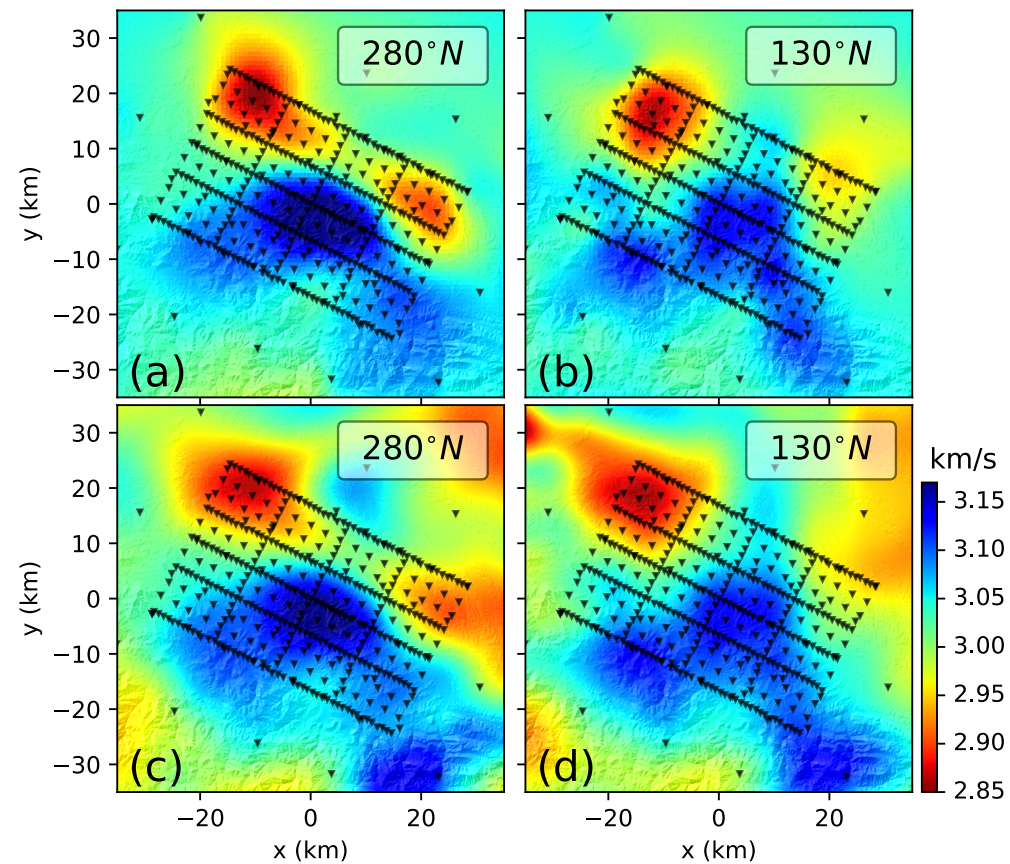

Figure 10. (a, b) eikonal phase velocity models inverted from the travel times shown in Fig. $8 \mathrm{a}$ and $\mathrm{b}$ respectively, $(\mathrm{c}, \mathrm{d})$ expected smooth eikonal phase velocity models obtained for the Atlantic (c) and Mediterranean sea (d) directions.
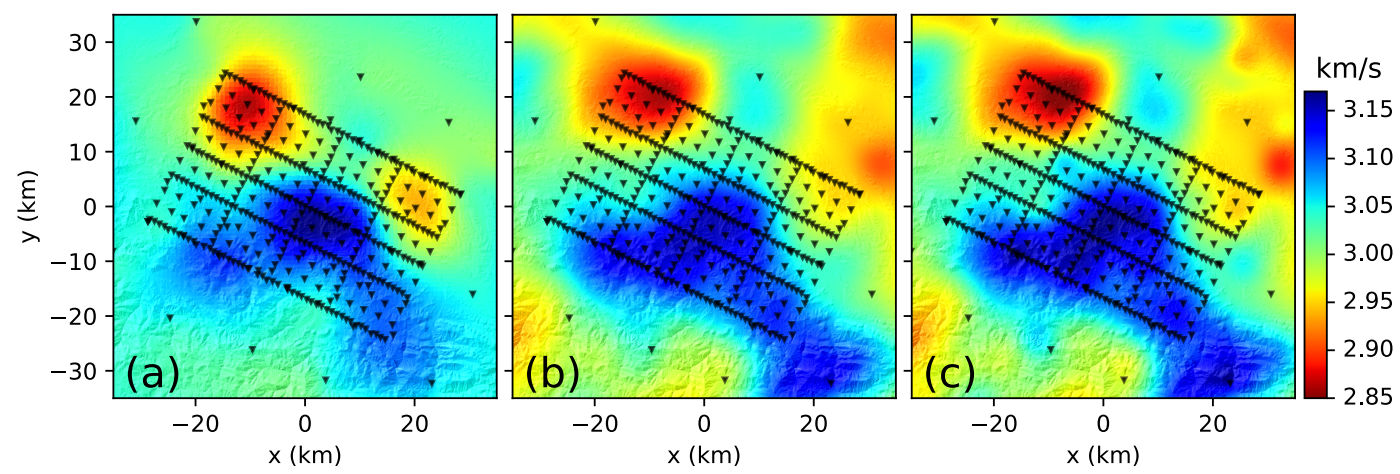

Figure 11. (a) Eikonal phase velocity models obtained by averaging models from directions N280 and N130 (10a,b). (b) Eikonal phase velocity model obtained from a complete azimuthal coverage. (c) True structural phase velocity model. 


\section{Application to the Maupasacq dataset}

\section{1 data pre-processing}

We pre-process the vertical component records as for the polarization analysis presented above. After removing the anomalous traces, the seismograms are deconvolved from their instrumental response, detrended, re-sampled at 2.5 samples per second, and cut into one-hour non overlapping time windows.

\subsection{Extraction of coherent wave trains by iterative matched filtering}

We apply the matched filtering approach at a number of periods spaced logarithmically between 2 and $9 \mathrm{~s}$. To mitigate the instrumental noise level in the seismograms, we use only the broad-band stations for periods above $7 \mathrm{~s}$ (Fig. 1, BB and PBB), the short period and broad-band stations for periods between 3 and $7 \mathrm{~s}$ (BB, PBB and SP) and all the stations for periods below $3 \mathrm{~s}$ (BB, PBB, SP and GN). Inside a given time window, we can usually extract several (sometimes up to 10) coherent wave fronts. We only keep the wave fronts whose average phase velocity corresponds to the fundamental mode Rayleigh wave. The phase velocity ranges used to isolate the Rayleigh wave component are $2.8-3.2 \mathrm{~km} / \mathrm{s}$ at period $5.6 \mathrm{~s}, 2.6-3.0 \mathrm{~km} / \mathrm{s}$ at period $3.48 \mathrm{~s}$ and $2.4-2.8 \mathrm{~km} / \mathrm{s}$ at period $2.34 \mathrm{~s}$ (Fig. 12). The first detections (dark red dots on Fig. 12) are in good agreement with the dominant noise sources previously identified with the polarization and beamforming analyses. Interestingly, the later detections, which correspond to less energetic noise sources, often come from other back-azimuths. Thus, by iterating and exploiting all the coherent but less energetic arrivals, we can improve the azimuthal coverage very significantly. However, very few arrivals are detected in the North-East and South-West directions.

\subsection{Results of matched filtering}

The MFCFs obtained for similar directions are averaged over $5^{\circ}$ azimuthal bins to increase the signal to noise ratio. Further details about the temporal variation and the convergence rate of the MFCF are given in the supplementary materials. The MFCFs obtained at each station for period $5.2 \mathrm{~s}$ for the two back-azimuths $\mathrm{N} 280^{\circ}$ and $\mathrm{N} 130^{\circ}$ are displayed on Fig. 13a,d. The MFCFs are ordered as a function of their distance from the noise source. The origin time is defined as the onset time at the center of the array. The 

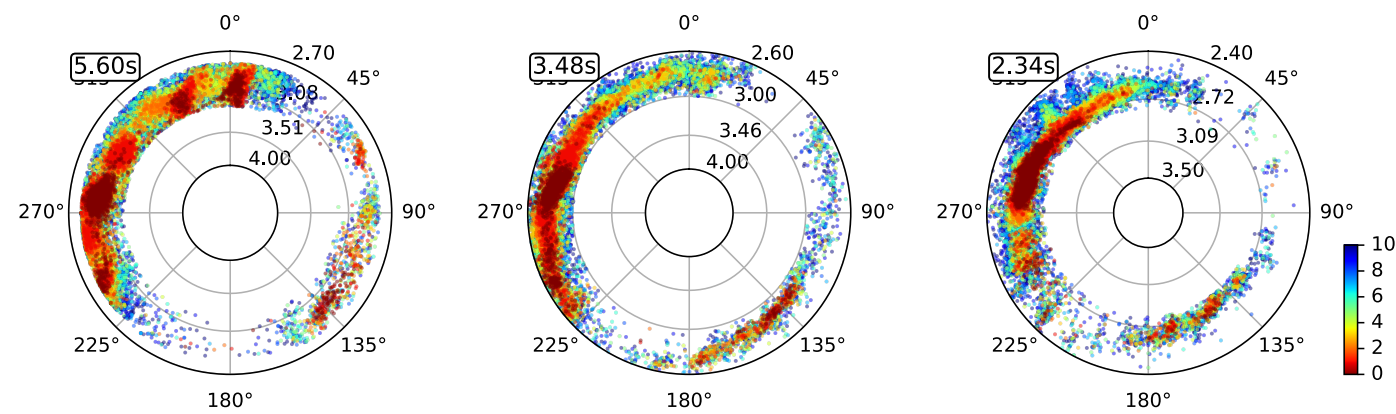

Figure 12. Detections of coherent fundamental mode Rayleigh wave trains during the 6 months of the Maupasacq experiment at three different periods: $5.60 \mathrm{~s}$ (left), $3.48 \mathrm{~s}$ (middle), and $2.34 \mathrm{~s}$ (right). Each dot corresponds to one extraction inside a 1-hr time window. The colors indicate the extraction rank ( 0 stands for the first extraction). The radial ticks correspond to phase velocities in $\mathrm{km} / \mathrm{s}$.

travel time and amplitude fields derived from the averaged MFCF at each station for the two directions are shown respectively on Fig. 13b, c and 13e, f. Movies showing the propagation of the extracted surface wave fronts across the network for several back azimuths and periods are given in the supplementary materials.

Significant distortions of the travel time field can be observed as a result of lateral variations of velocity beneath the array. For example, the wavefront curvature observed for the back azimuth $\mathrm{N} 280^{\circ}$ (Fig. 13b) in the north-eastern part of the array reveals the low velocity anomaly of the Arzacq basin. We also observe significant amplitude variations within the array, ranging from about 0.25 to 2 at period $5.2 \mathrm{~s}$ (Fig. 13c,f). The lateral distribution of the amplitudes vary with the incoming direction, which suggests that this distribution is firstly controlled by the heterogeneities that are crossed by the waves, rather than local structural amplifications. For example, the higher amplitudes observed in the Arzacq basin for the $\mathrm{N} 280^{\circ}$ direction (Fig. 13c) results from the focusing of the wave front produced by the negative velocity anomaly in the North-East corner of the array.

[Fig. 13] 


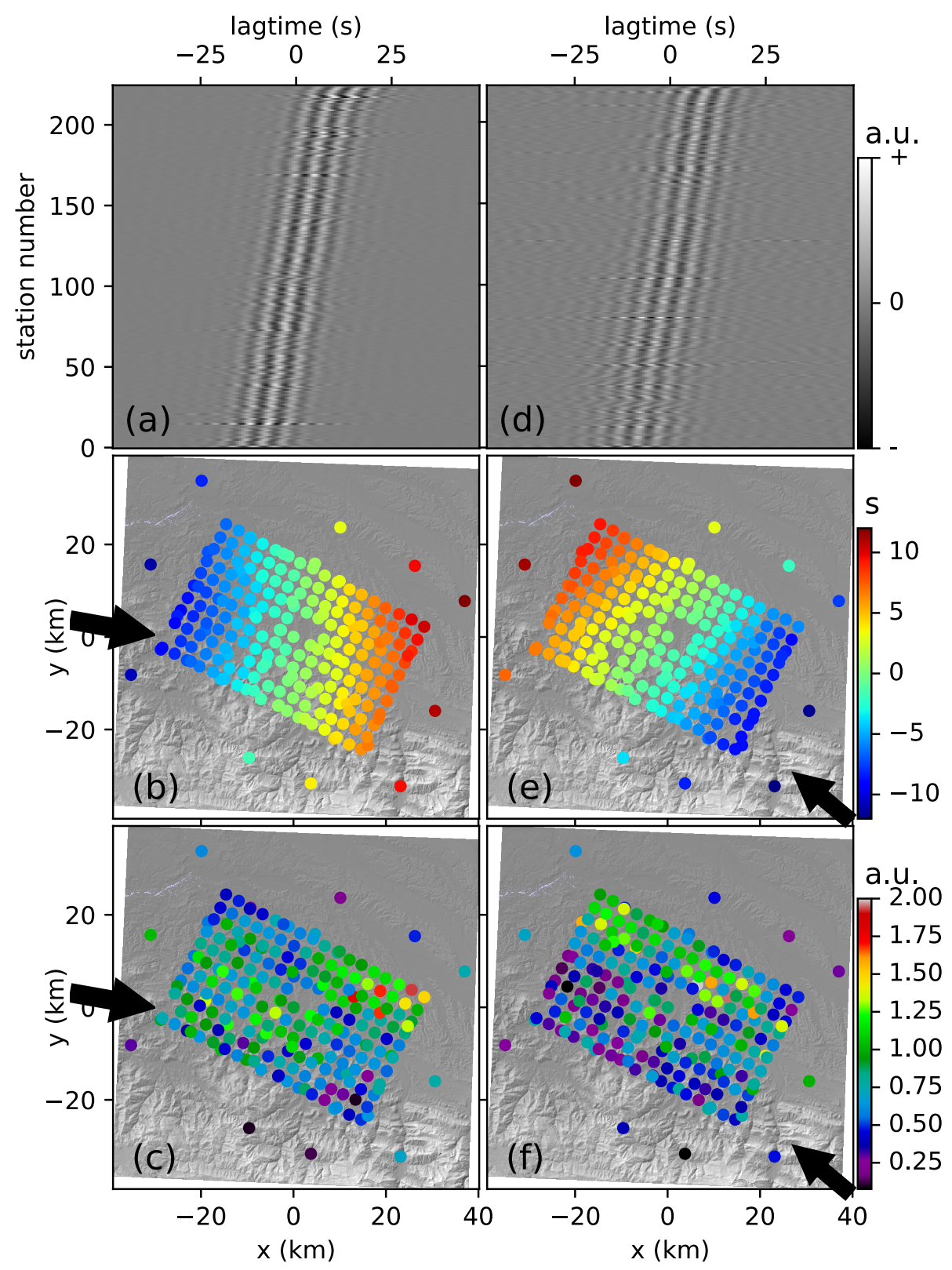

Figure 13. Matched filtering results obtained for the broad-band and short period sensors at period 5.2s, for the two directions $280^{\circ}$ (a-c) and $130^{\circ}$ (d-f) (black arrows) averaged over the full recording period. (a) Average MFCFs. (b) Travel time field obtained from the maximum lag time of the average MFCFs, expressed in s. (c) Amplitude field derived from the average MFCFs. (d-f) same as (a-c) for a the $130^{\circ}$ back-azimuth. 


\subsection{Phase velocity maps}

We use the regularized interpolation approach to estimate the eikonal phase velocity dispersion map for each back azimuth from the average MFCFs (as exemplified on Fig. 13b, e). We start the inversion using the wave fronts originating from the Atlantic direction (from the average MFCFs obtained for the back-azimuths between N280 ${ }^{\circ}$ and $\left.\mathrm{N} 285^{\circ}\right)$ at the longest period $(9 \mathrm{~s})$ assuming a homogeneous $3.1 \mathrm{~km} / \mathrm{s}$ prior model based on the average slowness measured by beamforming. The regularization parameters $(\alpha, \beta, \gamma)$ in eq. (10) are adjusted to balance all the terms of the misfit function. The resulting phase slowness model is then used as the prior model for the next period (8.32 s) shifted by a constant slowness value to fit the mean slowness of the detected wave fronts at period $8.32 \mathrm{~s}$. The procedure is repeated for the 20 periods spaced logarithmically down to period $2 \mathrm{~s}$. The phase slowness models obtained at each period for the incoming Atlantic direction are then used as prior models to invert the travel time fields in the other directions. The azimuthal average of the phase velocity models obtained are shown in Fig. 14 .

[Fig. 14] 

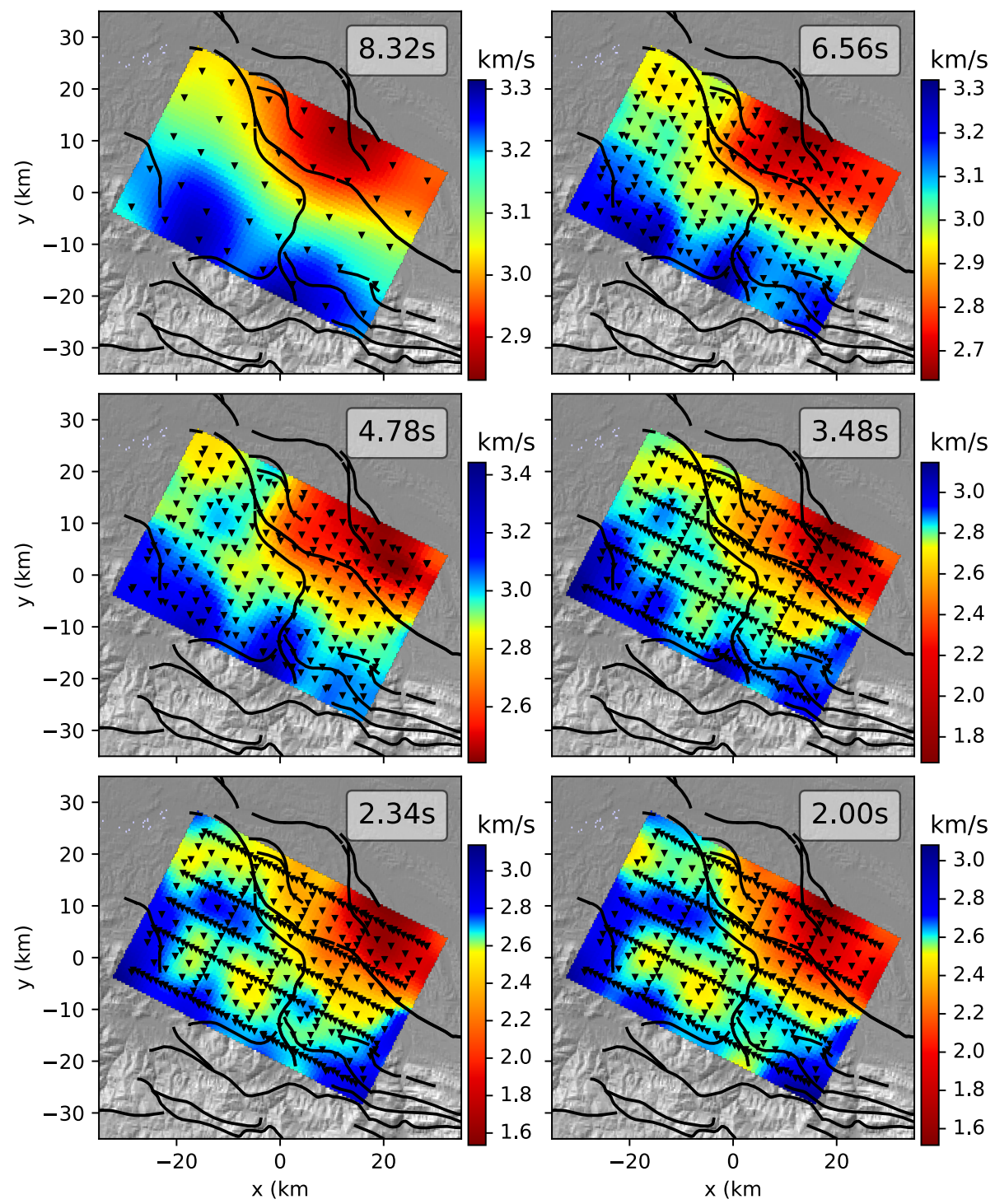

Figure 14. Rayleigh wave phase velocity models obtained at 6 periods between 9 and $2 \mathrm{~s}$, in $\mathrm{km} / \mathrm{s}$. 


\section{Discussion}

\subsection{Comparison between matched filtering coherent wave field imaging and standard ambient noise tomography}

The matched filtering method shares many similarities with standard ambient noise tomography. However, while both methods exploit the surface waves present in the ambient noise field for passive imaging, they do differ in several aspects.

First, in contrast to standard ambient noise tomography, the matched filtering approach does not rely on the implicit assumptions of a diffusive ambient noise field (Lobkis \& Weaver, 2001) or of a spatially uniform distribution of uncorrelated noise sources (Roux et al., 2005). Instead, it exploits the strong directivity of noise sources to separate and extract coherent wave trains. While ambient noise correlation can usually provide relatively accurate travel time information even with heterogeneous noise source distributions or imperfectly diffuse wave fields, the matched filter approach better exploits the strong directivity of ambient noise fields. We have shown that the matched filtering method remains valid in the case of interfering wave trains originating from different directions, as observed with the Maupasacq array. The iterative extraction of coherent waves allows us to exploit sources from a broad range of azimuths thanks to the secondary noise sources that are most of the time buried beneath the predominant Atlantic and Mediterranean noise sources. Since the azimuthal averaging of eikonal phase velocity map can mitigate the error due to the eikonal approximation (Bodin \& Maupin, 2008), we believe that the improved azimuthal coverage will ultimately lead to more robust isotropic tomographic models with less artefacts.

Second, the standard noise correlation method often implies some aggressive nonlinear pre-processing filters like spectral whitening or temporal normalization (Bensen et al., 2007), which annihilate the amplitude information. Although it is usually admitted that those filters should be avoided for applications that try to exploit the amplitude information, no clear consensus can be found in the literature about the optimal pre-processing to simultaneously ensure a good reconstruction of the amplitudes and convergence of the noise correlations (e.g., Mordret et al., 2013; Liu et al., 2015; Bowden et al., 2015, 2017). With the matched filtering approach, since we normalize the correlations by the energy of the reference wavelet, the amplitude information is naturally preserved. The amplitude fields obtained by matched filtering should open important per- 
spectives to better constrain attenuation and seismic anisotropy beneath dense local or regional seismic arrays.

Third, in ambient noise tomography, exploiting the noise correlation functions for inter-station distances smaller than a few wavelengths is generally challenging. In that case, surface waves are observed in the near field, which hinders the estimation of phase and group travel times, and errors due to heterogeneous noise source distributions become prominent (Weaver et al., 2009). For these reasons, close station pairs are often discarded (Bensen et al., 2007), which has a detrimental effect on the spatial coverage. The matched filtering approach does not suffer from this limitation.

Fourth, in the matched filtering approach, the separation and extraction of the different coherent wave trains scale with the number of sensors, while noise correlation scales with the square number of sensors when considering all the station pairs. Therefore, matched filtering can be used to obtain a tomographic image with lower computational cost. On the other hand, since noise correlations exploit the redundancy of information between a large number of station pairs, this can reduce the errors in the travel time estimates.

The main limitation of the matched filtering approach comes from the geometry of the acquisition. It first needs to be sufficiently dense to sample the wave field without spatial aliasing. In addition, the aperture of the array must be sufficiently large to be able to separate wave fields originating from nearby directions. In other words, the results of matched filtering will be controlled by the array response function at the periods considered (see supplementary information).

\subsection{Going from eikonal to Helmholtz tomography}

Despite the long term averaging of the MFCFs (over 6 months), the amplitude fields obtained are still noisy (Fig. 13c, f). A first source of problem is probably due to the use of different types of instruments and from an imperfect knowledge of their responses, especially for the SP sensors. In addition, since the periods considered in this study are well below the cut-off period of the SP and GN sensors, we have to face a significant level of instrumental noise. This will limit our capacity to exploit the amplitudes with Helmholtz tomography (Lin \& Ritzwoller, 2011). In any case, amplitude fields still constitute untapped important sources of information that should allow us to further improve over the results of eikonal tomography in the near future. 


\subsection{Lateral variations of phase velocities beneath the Maupasacq array}

The phase velocity maps show strong lateral variations, revealing the complexity of the structures in the upper $10 \mathrm{~km}$. The main shallow feature is the low velocity anomaly in the north-eastern part of the model, which coincides with the Arzacq basin, a Tertiary unit separated from the Mauleon basin by the North Pyrenean Front Thrust (Fig. 1). The Mauleon basin, to the south west, is filled with Cretaceous calcareous and flysch rocks, which are characterized by much higher phase velocities. The low velocity anomaly observed in the south-western part of the Mauleon basin for periods shorter than $3.5 \mathrm{~s}$ are related to a large syncline approximately oriented along a WNW-ESE direction. It is nicely correlated with shallow post and syn-rift sedimentary deposits visible in the surface geological maps of the area (e.g., Masini et al., 2014). The phase velocity maps at periods longer than $4 \mathrm{~s}$ show a different and simpler pattern. In these maps, a sharp transition is observed which marks the limit between a high velocity domain in the south and a slower domain in the northernmost part of the Mauleon basin. Interestingly, this high velocity region is found on the top of the fast velocity anomaly imaged in Y. Wang et al. (2016), which has been interpreted as a mantle body exhumed during the Cretaceous episode of rifting. This would suggest that the top of the basement is at a much shallower depth in the southern part of the Mauleon basin, in good agreement with the geological sections recently published for this area (e.g., Saspiturry et al., 2019; GómezRomeu et al., 2019).

\section{Conclusions}

We analyzed the ambient noise recorded during 6 months by the large-N Maupasacq array in the Arzacq-Mauleon basins (Western Pyrenees, France) in the period band 2$9 \mathrm{~s}$. Our study revealed strong coherent sources from several directions corresponding to the Galicia $\left(\mathrm{N} 275^{\circ}\right)$, the northern Atlantic $\left(\mathrm{N} 340^{\circ}\right)$ and the Mediterranean sea $\left(\mathrm{N} 130^{\circ}\right)$, in good agreement with the directions previously identified by Chevrot et al. (2007). This observation motivated the development of an iterative matched filtering method to separate and extract coherent wave fronts from the ambient noise field, which has been validated on a synthetic test case. We have shown that robust phase velocity maps can be obtained with the eikonal approach, after averaging the eikonal phase velocity maps obtained for the different incoming azimuths. The final phase velocity maps at short pe- 
riod $(2-3 \mathrm{~s})$ are nicely correlated with surface geology. At longer period $(>4 \mathrm{~s})$, they reveal the deep architecture of the Arzacq and Mauleon basins.

\section{Acknowledgments}

This work is part of the OROGEN research project, a tripartite partnership between the French CNRS, Total and BRGM. We thank the CNRS and Observatoire Midi Pyrénées (OMP) who provided and deployed the broad-band temporary stations (BB), CSIC who provided and installed the 191 geophone nodes (GN), Seismotech for the installation, maintenance and harvesting of the 197 Short Period recorders (SP), and the Maupasacq Team, who settled the stations on the field and collected the data. We are grateful to the two anonymous reviewers for their constructive criticisms that greatly helped improve the content of this manuscript. Data from the permanent broad-band (PBB) stations are part of the Resif-RLBP French permanent network, and are accessible via the RESIF data center (RESIF, 1995). The data acquired in the framework of the OROGEN project (BB, SP and GN stations) are not publicly available during the time of the project. Researchers can gain access to the data by contacting the OROGEN project leaders at this address : http://www.orogen-project.com/contact. The MFCFs are provided in the supplementary materials.

\section{References}

Bensen, G. D., Ritzwoller, M. H., Barmin, M. P., Levshin, A. L., Lin, F., Moschetti, M. P., .. Yang, Y. (2007, June). Processing seismic ambient noise data to obtain reliable broad-band surface wave dispersion measurements. Geophysical Journal International, 169(3), 1239-1260. doi: 10.1111/j.1365-246X.2007.03374.x

Ben-Zion, Y., Vernon, F. L., Ozakin, Y., Zigone, D., Ross, Z. E., Meng, H., ... Barklage, M. (2015, July). Basic data features and results from a spatially dense seismic array on the San Jacinto fault zone. Geophysical Journal International, 202(1), 370-380. doi: 10.1093/gji/ggv142

Bodin, T., \& Maupin, V. (2008, February). Resolution potential of surface wave phase velocity measurements at small arrays. Geophysical Journal International, 172(2), 698-706. doi: 10.1111/j.1365-246X.2007.03668.x

Bowden, D. C., Tsai, V. C., \& Lin, F. C. $\quad$ (2015). Site amplification, attenua- 
tion, and scattering from noise correlation amplitudes across a dense array in Long Beach, CA. Geophysical Research Letters, 42(5), 1360-1367. doi: 10.1002/2014GL062662

Bowden, D. C., Tsai, V. C., \& Lin, F.-C. (2017, December). Amplification and Attenuation Across USArray Using Ambient Noise Wavefront Tracking. Journal of Geophysical Research: Solid Earth, 122(12), 10,086-10,101. doi: 10.1002/ 2017JB014804

Brenguier, F., Kowalski, P., Ackerley, N., Nakata, N., Boué, P., Campillo, M., ... Chaput, J. (2016, January). Toward 4d Noise-Based Seismic Probing of Volcanoes: Perspectives from a Large-N Experiment on Piton de la Fournaise Volcano. Seismological Research Letters, 87(1), 15-25. doi: 10.1785/0220150173

Cansi, Y. (1995, May). An automatic seismic event processing for detection and location: The P.M.C.C. Method. Geophysical Research Letters, 22(9), 10211024. doi: 10.1029/95GL00468

Chevrot, S., Sylvander, M., Benahmed, S., Ponsolles, C., Lefèvre, J. M., \& Paradis, D. (2007). Source locations of secondary microseisms in western Europe: Evidence for both coastal and pelagic sources. Journal of Geophysical Research: Solid Earth, 112(B11). doi: 10.1029/2007JB005059

Curtis, A., \& Halliday, D. (2010, January). Directional balancing for seismic and general wavefield interferometry. GEOPHYSICS, 75(1), SA1-SA14. doi: 10 $.1190 / 1.3298736$

de Ridder, S. A. L., \& Biondi, B. L. (2015). Near-surface Scholte wave velocities at Ekofisk from short noise recordings by seismic noise gradiometry. Geophysical Research Letters, 42(17), 7031-7038. (_eprint: https://agupubs.onlinelibrary.wiley.com/doi/pdf/10.1002/2015GL065027) doi: 10.1002/2015GL065027

de Ridder, S. A. L., \& Dellinger, J. (2011, May). Ambient seismic noise eikonal tomography for near-surface imaging at Valhall. The Leading Edge, 30(5), 506512. doi: $10.1190 / 1.3589108$

Ermert, L., Sager, K., Afanasiev, M., Boehm, C., \& Fichtner, A. (2017). Ambient Seismic Source Inversion in a Heterogeneous Earth: Theory and Application to the Earth's Hum. Journal of Geophysical Research: Solid Earth, 122(11), 9184-9207. doi: 10.1002/2017JB014738 
Fan, W., de Groot-Hedlin, C. D., Hedlin, M. A. H., \& Ma, Z.

(2018, November). Using surface waves recorded by a large mesh of three-element arrays to detect and locate disparate seismic sources. Geophysical Journal International, 215(2), 942-958. doi: 10.1093/gji/ggy316

Fichtner, A., Stehly, L., Ermert, L., \& Boehm, C. (2017, February). Generalized interferometry - I: theory for interstation correlations. Geophysical Journal International, 208(2), 603-638. doi: 10.1093/gji/ggw420

Gómez-Romeu, J., Masini, E., Tugend, J., Ducoux, M., \& Kusznir, N.

$(2019$ June). Role of rift structural inheritance in orogeny highlighted by the Western Pyrenees case-study. Tectonophysics, 766, 131-150. doi: 10.1016/ j.tecto.2019.05.022

Hand, E. (2014, August). A boom in boomless seismology. Science, 345(6198), 720 721. doi: $10.1126 /$ science.345.6198.720

Hansen, S. M., \& Schmandt, B. (2015). Automated detection and location of microseismicity at Mount St. Helens with a large-N geophone array. Geophysical Research Letters, 42(18), 7390-7397. doi: 10.1002/2015GL064848

Jensen, F. B., Kuperman, W. A., Porter, M. B., \& Schmidt, H. (2000). Computational Ocean Acoustics. Springer Science \& Business Media. (Google-Books-ID: QHtx4zYPbzMC)

Landès, M., Hubans, F., Shapiro, N. M., Paul, A., \& Campillo, M. (2010). Origin of deep ocean microseisms by using teleseismic body waves. Journal of Geophysical Research: Solid Earth, 115(B5). doi: 10.1029/2009JB006918

Lin, F.-C., Li, D., Clayton, R. W., \& Hollis, D. (2013, July). High-resolution 3D shallow crustal structure in Long Beach, California: Application of ambient noise tomography on a dense seismic arrayNoise tomography with a dense array. Geophysics, 78(4), Q45-Q56. (Publisher: GeoScienceWorld) doi: $10.1190 /$ geo2012-0453.1

Lin, F. C., Moschetti, M. P., \& Ritzwoller, M. H. (2008). Surface wave tomography of the western United States from ambient seismic noise: Rayleigh and Love wave phase velocity maps. Geophysical Journal International, 173(1), $281-298$.

Lin, F.-C., \& Ritzwoller, M. H. (2011, September). Helmholtz surface wave tomography for isotropic and azimuthally anisotropic structure. Geophysical Journal 
International, 186(3), 1104-1120. doi: 10.1111/j.1365-246X.2011.05070.x

Lin, F.-C., Ritzwoller, M. H., \& Snieder, R. (2009, June). Eikonal tomography: surface wave tomography by phase front tracking across a regional broad-band seismic array. Geophysical Journal International, 177(3), 1091-1110. doi: 10.1111/j.1365-246X.2009.04105.x

Liu, X., Ben-Zion, Y., \& Zigone, D. (2015, November). Extracting seismic attenuation coefficients from cross-correlations of ambient noise at linear triplets of stations. Geophysical Journal International, 203(2), 1149-1163. doi: $10.1093 /$ gji $/$ ggv357

Lobkis, O. I., \& Weaver, R. L. (2001). On the emergence of the Green's function in the correlations of a diffuse field. The Journal of the Acoustical Society of America, 110(6), 3011-3017. doi: 10.1121/1.1417528

Longuet-Higgins, M. S. (1950, September). A Theory of the Origin of Microseisms. Philosophical Transactions of the Royal Society of London. Series A, Mathematical and Physical Sciences, 243(857), 1-35. doi: 10.1098/rsta.1950.0012

Masini, E., Manatschal, G., Tugend, J., Mohn, G., \& Flament, J.-M. (2014, September). The tectono-sedimentary evolution of a hyper-extended rift basin: the example of the Arzacq-Mauléon rift system (Western Pyrenees, SW France). International Journal of Earth Sciences, 103(6), 1569-1596. doi: 10.1007/s00531 $-014-1023-8$

Meschede, M., Stutzmann, E., Farra, V., Schimmel, M., \& Ardhuin, F. (2017, October). The Effect of Water-Column Resonance on the Spectra of Secondary Microseism P-waves. Journal Of Geophysical Research-solid Earth, 122(10), 8121-8142. doi: 10.1002/2017JB014014

Mordret, A., Shapiro, N., Singh, S., Roux, P., \& Barkved, O. ～(2013, March). Helmholtz tomography of ambient noise surface wave data to estimate Scholte wave phase velocity at Valhall Life of the Field. GEOPHYSICS, 78(2), WA99WA109. doi: 10.1190/geo2012-0303.1

Nakata, N., Boué, P., Brenguier, F., Roux, P., Ferrazzini, V., \& Campillo, M. (2016). Body and surface wave reconstruction from seismic noise correlations between arrays at Piton de la Fournaise volcano. Geophysical Research Letters, 43(3), 2015GL066997. doi: 10.1002/2015GL066997

Park, J., Vernon, F. L., \& Lindberg, C. R. ～(1987, November). Frequency 
dependent polarization analysis of high-frequency seismograms.

nal of Geophysical Research: Solid Earth, 92(B12), 12664-12674.

doi: 10.1029/JB092iB12p12664

Pedersen, H. A., \& Colombi, A. (2018, August). Body waves from a single source area observed in noise correlations at arrival times of reflections from the 410 discontinuity. Geophysical Journal International, 214(2), 1125-1135. doi: $10.1093 /$ gji $/$ ggy191

Polychronopoulou, K., Lois, A., Martakis, N., Chevrot, S., Sylvander, M., Diaz, J., ... others (2018). Broadband, short-period or geophone nodes? quality assessment of passive seismic signals acquired during the maupasacq experiment. First Break, 36(4), 71-75.

RESIF. (1995). Resif-rlbp french broad-band network, resif-rap strong motion network and other seismic stations in metropolitan france; resif - réseau sismologique et géodésique français. doi: 10.15778/RESIF.FR

Ritzwoller, M. H., Lin, F.-C., \& Shen, W. (2011, September). Ambient noise tomography with a large seismic array. Comptes Rendus Geoscience, 343(8-9), 558570. doi: $10.1016 /$ j.crte.2011.03.007

Roux, P., \& Ben-Zion, Y. (2017, October). Rayleigh phase velocities in Southern California from beamforming short-duration ambient noise. Geophysical Journal International, 211(1), 450-454. doi: 10.1093/gji/ggx316

Roux, P., Gimbert, F., Nanni, U., Helmstetter, A., Urruty, B., Garambois, S., ... Langlais, M. (2016, December). Measuring and Modeling the Effects of Meltwater Changes at Glaciers. AGU Fall Meeting Abstracts, 2016, EP33E-06.

Roux, P., Moreau, L., Lecointre, A., Hillers, G., Campillo, M., Ben-Zion, Y., ... Vernon, F. (2016, August). A methodological approach towards high-resolution surface wave imaging of the San Jacinto Fault Zone using ambient-noise recordings at a spatially dense array.

Geophysical Journal International, 206 (2), 980-992. doi: 10.1093/gji/ggw193

Roux, P., Sabra, K. G., Kuperman, W. A., \& Roux, A. (2005). Ambient noise cross correlation in free space: Theoretical approach. The Journal of the Acoustical Society of America, 117(1), 79-84. doi: 10.1121/1.1830673

Sager, K., Ermert, L., Boehm, C., \& Fichtner, A. ～(2018, January). Towards full waveform ambient noise inversion. Geophysical Journal International, 212(1), 
566-590. doi: 10.1093/gji/ggx429

Saspiturry, N., Razin, P., Baudin, T., Serrano, O., Issautier, B., Lasseur, E., ...

Leleu, S. (2019, June). Symmetry vs. asymmetry of a hyper-thinned rift: Example of the Mauléon Basin (Western Pyrenees, France). Marine and Petroleum Geology, 104, 86-105. doi: 10.1016/j.marpetgeo.2019.03.031

Sethian, J. A. (1996, February). A fast marching level set method for monotonically advancing fronts. Proceedings of the National Academy of Sciences, 93(4), 1591-1595. doi: 10.1073/pnas.93.4.1591

Shapiro, N. M., \& Campillo, M. (2004). Emergence of broadband Rayleigh waves from correlations of the ambient seismic noise. Geophysical Research Letters, $31(7)$.

Shapiro, N. M., Campillo, M., Stehly, L., \& Ritzwoller, M. H. (2005, March). HighResolution Surface-Wave Tomography from Ambient Seismic Noise. Science, 307(5715), 1615-1618. doi: 10.1126/science.1108339

Sigloch, K., \& Nolet, G. (2006). Measuring finite-frequency body-wave amplitudes and traveltimes. Geophysical Journal International, 167(1), 271-287. doi: 10 $.1111 /$ j.1365-246X.2006.03116.x

Smith, W. H. F., \& Wessel, P. (1990, March). Gridding with continuous curvature splines in tension. Geophysics, 55(3), 293-305. doi: 10.1190/1.1442837

Snieder, R. (2004). Extracting the Green's function from the correlation of coda waves: A derivation based on stationary phase. Physical Review E, 69(4), 046610.

Stacey, R. (1988, December). Improved transparent boundary formulations for the elastic-wave equation. Bulletin of the Seismological Society of America, 78(6), 2089-2097.

Stutzmann, E., Roult, G., \& Astiz, L. (2000). Geoscope station noise levels, , 90(3), 690-701. Bulletin of the Seismological Society of America, 90(3), 690-701.

Taylor, G., Rost, S., Houseman, G. A., \& Hillers, G. (2019, March). Near-surface structure of the North Anatolian Fault zone from Rayleigh and Love wave tomography using ambient seismic noise. Solid Earth, 10(2), 363-378. doi: https://doi.org/10.5194/se-10-363-2019

Turin, G. (1960, June). An introduction to matched filters. IRE Transactions on Information Theory, 6(3), 311-329. doi: 10.1109/TIT.1960.1057571 
Vergne, J., Lehujeur, M., Schmittbuhl, J., Zigone, D., \& Chenadec, A. L. June). Probing the Crustal Structure Around Deep Geothermal Reservoirs with Ambient Seismic Noise - The Estof Pilot Study. In 79th EAGE Conference and Exhibition 201\%. doi: 10.3997/2214-4609.201700741

Vidale, J. E. (1986). Complex polarization analysis of particle motion. Bulletin of the Seismological society of America, 76 (5), 1393-1405.

Villaseñor, A., Yang, Y., Ritzwoller, M. H., \& Gallart, J. (2007, June). Ambient noise surface wave tomography of the Iberian Peninsula: Implications for shallow seismic structure. Geophysical Research Letters, 34(11), L11304. doi: 10.1029/2007GL030164

Wang, J., Tilmann, F., White, R. S., Soosalu, H., \& Bordoni, P. $\quad$ (2008). $\quad$ Application of multichannel Wiener filters to the suppression of ambient seismic noise in passive seismic arrays. The Leading Edge, 7(2), 120-280. doi: $10.1190 / 1.2840372$

Wang, Y., Allam, A., \& Lin, F.-C. (2019). Imaging the Fault Damage Zone of the San Jacinto Fault Near Anza With Ambient Noise Tomography Using a Dense Nodal Array. Geophysical Research Letters, 46(22), 12938-12948. (_eprint: https://agupubs.onlinelibrary.wiley.com/doi/pdf/10.1029/2019GL084835) doi: 10.1029/2019GL084835

Wang, Y., Chevrot, S., Monteiller, V., Komatitsch, D., Mouthereau, F., Manatschal, G., ... Martin, R. (2016, June). The deep roots of the western Pyrenees revealed by full waveform inversion of teleseismic P waves. Geology, 44(6), 475-478. doi: $10.1130 / \mathrm{G} 37812.1$

Wapenaar, K., Ruigrok, E., van der Neut, J., \& Draganov, D. $\quad$ (2011, January). Improved surface-wave retrieval from ambient seismic noise by multidimensional deconvolution. Geophysical Research Letters, 38(1), L01313. doi: $10.1029 / 2010$ GL045523

Weaver, R., Froment, B., \& Campillo, M. (2009). On the correlation of nonisotropically distributed ballistic scalar diffuse waves. The Journal of the Acoustical Society of America, 126(4), 1817-1826. doi: 10.1121/1.3203359

Yao, H., \& van der Hilst, R. D. (2009, November). Analysis of ambient noise energy distribution and phase velocity bias in ambient noise tomography, with application to SE Tibet. Geophysical Journal International, 179, 1113-1132. doi: 
10.1111/j.1365-246X.2009.04329.x 